\title{
A comparative study of meta-heuristic and conventional optimization techniques of grid connected photovoltaic system
}

\author{
Mamadou Traore ${ }^{1}$, Alphousseyni Ndiaye ${ }^{2}$, Senghane Mbodji ${ }^{3}$ \\ ${ }^{1,2}$ Research Team Energetic System and Efficiency, Department of Physics, Alioune Diop University of Bambey, \\ Bambey, Senegal \\ ${ }^{3}$ Research Team in Renewable Energies, Materials and Laser of Department of Physics, Alioune Diop University of \\ Bambey, Bambey, Senegal
}

\section{Article Info \\ Article history: \\ Received Mar 22, 2021 \\ Revised Sep 24, 2021 \\ Accepted Oct 1, 2021}

\section{Keywords:}

Renewable energy PV-Grid system Optimization algorithm Proportional integral

\begin{abstract}
This paper presents the meta-heuristic and conventional optimizations techniques for the grid connected photovoltaic solar system. The perturb and observe (P\&O) and particle swarm optimization (PSO) algorithms are proposed to track the maximum power point (MPP) of the photovoltaic solar system (PVSS). The regularization of the current supplied into the grid is ensured by the proportional integral (PI) corrector whose parameters are generated by the genetic algorithm (GA). The results of these two MPPT methods are compared and showed that the PSO is more efficient than the P\&O. The use of GA algorithm to determine PI parameters allowed to obtain $0.89 \%$ of total distortion harmonic (THD).
\end{abstract}

This is an open access article under the CC BY-SA license.

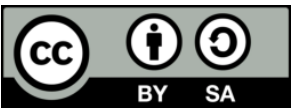

\section{Corresponding Author:}

Mamadou Traore

Research Team Energetic System and Efficiency, Department of Physics

Alioune Diop University of Bambey

Bambey, Senegal

Email: mamadou.traore@uadb.edu.sn

\section{INTRODUCTION}

Due to the environmental and economic context, the renewable energy plays an important role in the production and distribution global energy. This manifests itself through reduced greenhouse, gas emission, improved energy quality, better system efficiency and reliable service. Photovoltaic system (PV) is one of the types of renewables energy. But, the main problems of the PV system are the intermittence of its source and the dependence of its characteristics on climatic conditions and the quality of the energy injected into the grid.

Hence, several researchers have carried out some works to overcome its challenges by using optimizations techniques. There are many methods of power optimization. For example, in order to minimize power losses, an incremental conductance (IC) based variable step size Neuro-Fuzzy (NF) control is early proposed [1]. This method reduces consequently the power losses. Using a terminal sliding mode controller combined to PSO [2], it is shown that the PSO-TSMC offers the best results. With the PSO and GA algorithms, the PID and N-DPID MPPT controllers permitted a goog optimization's achievement [3]. The PSO provides a flexible response under fast-changing weather conditions. An artificial bee colony (ABC) integrated PO as MPPT algorithm is alos used for optimizing the duty cycle of a boost converter [4]. This proposed method allows for higher performance and greater precision. An approach based on a novel salp swarm optimization (SSO) demonstrated considerable success and reliability [5]. The Bat-P\&O, Bat-Beta, and Bat-IC MPPT are also studied and compared betwwen them [6]. It is noted that the Bat-Beta command 
performs better under all test conditions. A new proportional integral (PI) fractional order incremental (FOI) technique optimized by salp swarm algorithm (SSA) is developed in order to operate the PV system at the estimated PPM [7]. As a result, the authors remarked that their algorithm offers a better tracking capability than the others. A variable-weather-parameter (VWP) command is proposed [8]. And the simulation results showed that the applied approach is applicable for the tracking of the MPP. Considering a new Harris Hawk optimization [9], it is shown that the most important advantages of this approach is to allow quickly of the maximum power point. Proposing an asymmetrical interval type-2 fuzzy logic control (IT-2 AFLC) [10], P. Verma et al. [10] concluded that this technique has the maximum output power in all shading scenarios. The possibility of extracting the MPPT of each PV panel is demonstrated in a novel feedforward technique [11]. To optimize the PV energy production, the $\mathrm{P} \& \mathrm{O}$ and $\mathrm{InC}$ commands are improved [12]. The simulation results showed that IC MPPT control technique is more effective than P\&O. A modified P\&O algorithm study proved that the used method [13] is faster than P\&O conventional and efficiency is increased.

In the literature, many techniques are proposed to achieve better performance of the PV-grid system. A coordinated control [14] is used to reduce the output variation. In [15], with a nonlinear command, the THD reaches $2.44 \%$. To optimize the Proportional and the Proportional Integral controllers, an algorithm [16] permitted to reduce by $27 \%$ the THD. A modified droop controller [17] leaded to the control of the reactive power injection of the inverter in the situation where the voltages of each customer are less than $10.02 \%$ of the nominal voltage. By another method of control [18], it is shown that it possible to minimize the high frequency of the grid. The voltage control is also applied [19]. This approach keeps constant the dc link voltage. A predictive method reduces the THD to 1.26\% [20]. A novel Space Vector Modulation (SVM) whose aim is to reduce the THD is improved by Najafi et al. [21]. The results validated that the SVM allowed to obtain $1.76 \%$ of THD. Roselyn et al. [22], used a fuzzy logic command which operates significantly to impove the grid current. Another voltage control method [23] showed a THD which does not exceed 3.5\%. Applying hysteresis controller, Ganesan et al. [24] obtained an increase by $2.5 \%$ of the THD. In another hand, many techniques of control are used to control the output current [25]. All of them concluded that the cascade control gave a lower THD. Thus, our research is developped to use two metaheuristics techniques to optimize the PV power and impove the performance of a single-phase inverter connected to grid.

Therefore, in this work, a comparative review of the P\&O and the PSO is proposed. The both algorithms are used to extract the MPP of the PV under several variations of solar irradiation and the temperature. The objective of this comparative study is to choose the best efficiency to extract the MPP. On the $\mathrm{AC}$ side, the genetic algorithm under MATLAB is used to optimize the PI parameters. As we know, there are several methods to determine the parameters of a corrector: Ziegler-Nichols, Naslin, placement of the poles, etc. Each of them fixes at least theoretically one variable of the transfer function of the corrector. This is the difference with the proposed method (GA-PI). Hence, the principal objective of this work is to extract the MPP of the PV system and to inject into the grid a good quality of energy with a zero reactive power and a low THD.

\section{DESCRIPTION OF THE STUDIED SYSTEM}

The Figure 1 represents the studied system. It consists of a photovoltaic generator, a DC/ DC boost converter and a single-phase converter, low voltage electrical grid. And the systems for the optimisation of the power of the photovoltaic panel and the regulation of the output current of the single-phase inverter are illustrated.

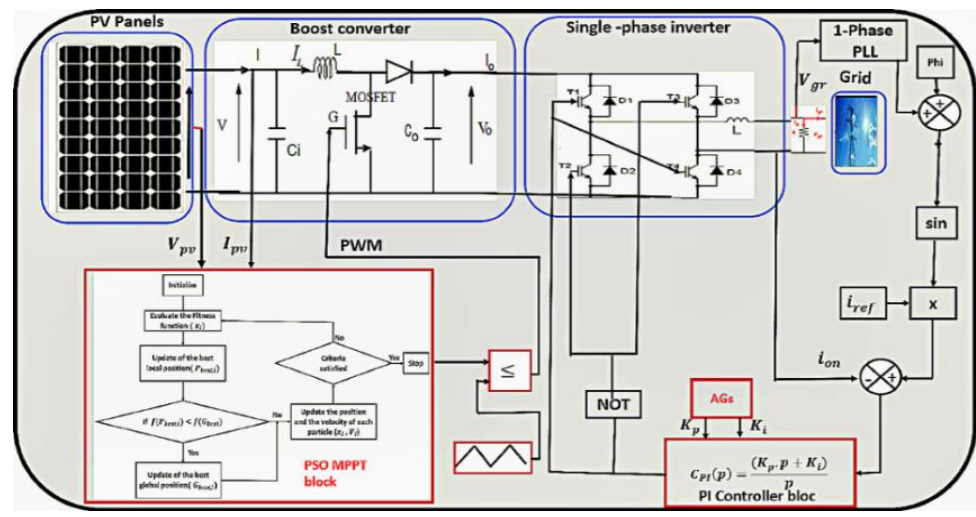

Figure 1. Studied system 


\subsection{PV panels}

There are several models of PV panels. The most popular model in power electronics is the single diode model as shown in Figure 2 (a) [26]. This is because it has a good compromise between precision and simplicity. The PV panel parameters is represented by (1). Figure 2 (b) shows the number of panels, the connection's types and PV parameters (open and short-circuit voltage and current respectively and maximum power).

$$
I_{p v}=I_{p h}-I_{S}\left[e^{\frac{V_{p v}+I_{p v} \cdot R_{S}}{n \cdot k \cdot T}}-1\right]-\frac{V_{p v}+I_{p v} \cdot R_{S}}{R_{S h}}
$$

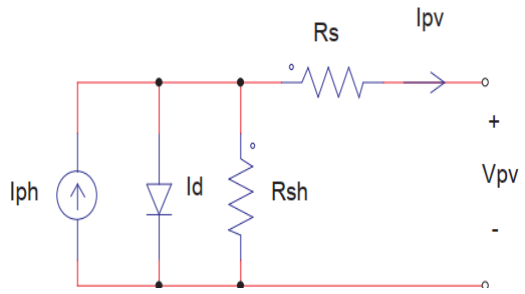

(a)
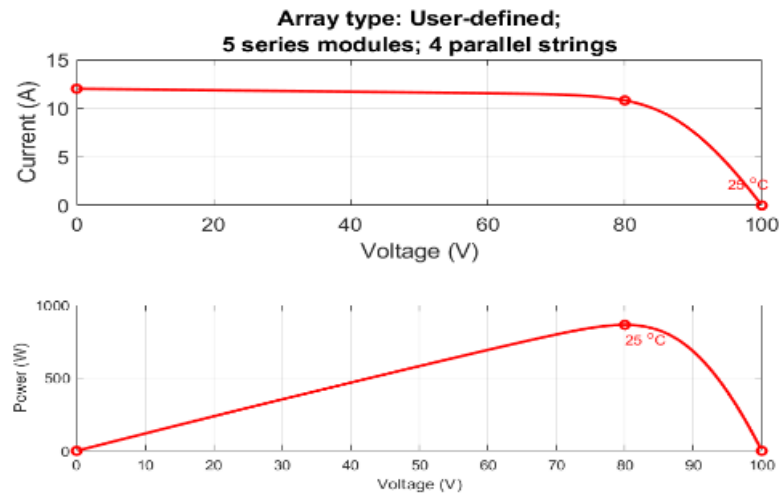

(b)

Figure 2. There figures are; (a) The electrical equivalent circuit of PV cell, (b) Typical PV characteristics at $1000 \mathrm{~W} / \mathrm{m}^{2}$ and $25^{\circ} \mathrm{C}$

Where Id is the diode saturation current, Ipv is the photo-current, Rsh is the shunt resistance and $R s$ is the series resistance, $\mathrm{k}$ is the Boltzmann's constant; $\mathrm{T}$ is the ambient temperature, $\mathrm{n}$ is the the diode factor of the junction. Table 1 represents the PV panel parameters used in thiswork.

Table 1. PV panel parameters

\begin{tabular}{lll}
\hline Parameter & \multicolumn{1}{c}{ Name } & \multicolumn{1}{c}{ Value } \\
\hline Pmax & Maximum Power & $43.2 \mathrm{~W}$ \\
Vmax & Maximum Voltage & $16 \mathrm{~V}$ \\
Imax & Maximum Current & $2.7 \mathrm{~A}$ \\
VOC & Voltage of the open circuit & $20 \mathrm{~V}$ \\
ISC & Current of the Short-circuit & $3 \mathrm{~A}$ \\
Rs & Series resistance & $0.57373 \Omega$ \\
Rsh & Shunt resistance & $103.3843 \Omega$ \\
a & Ideality factor & 0.89649 \\
Is & Saturation current & $9.4498 * 10-11$ \\
\hline
\end{tabular}

\subsection{Boost converter}

The boost converter is an electronic component which can convert the low voltage to high voltage. Its electrical circuit is represented by Figure 3. The boost converter is used in this work to provide a control signal that is generated by the $\mathrm{P} \& \mathrm{O}$ and PSO controls to the system to run at the maximum point and produce PV energy. 


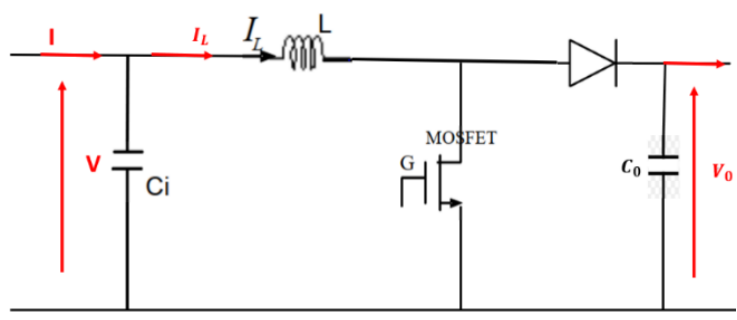

Figure 3. Boost converter

\section{PROPOSED METHODS}

\subsection{Algorithm of particle swarm optimization}

The PSO is an optimisation method that is able to reach a global best solution. It is a powerful and efficient method for the solution of complex optimisation questions. It has been modelled after the behaviour of birds. The Figure 4 illustrates the PSO approach.

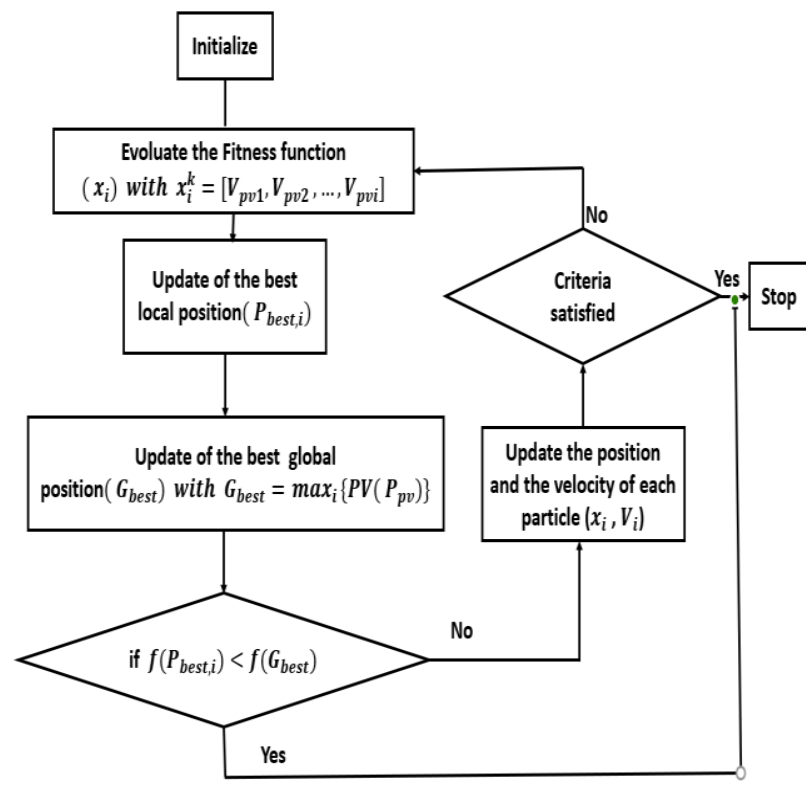

Figure 4. PSO algorithm

The PSO uses a population of agent, called particle. The latter is the solution to the problem. The (2) and (3) are used to update the position and velocity.

$$
\begin{aligned}
& V_{i}^{k+1}=w \cdot V_{i}^{k}+r_{1} \cdot c_{1}\left(P_{\text {best }, i}-x_{i}^{k}\right)+r_{2} \cdot c_{2}\left(G_{\text {best }}-x_{i}^{k}\right) \\
& x_{i}^{k+1}=x_{i}^{k}+V_{i}^{k+1}
\end{aligned}
$$

Where $\mathrm{k}$ is the number of iteration, it is the number of particle, $x_{i}$ and $V_{i}$ the position in the search space and velocity, respectively, $w$ is the inertia of particles, $P_{b e s t, i}$ and $G_{b e s t}$ are the best and the global best position of the particle, $c_{1}$ and $c_{2}$ are two constants called acceleration coefficients and $r_{1}$ and $r 2$ are random numbers. In this paper, equation 1 represents the objective function.

\subsection{Perturb and observe $(P \& O)$ algorithm}

This method allows the system to be disturbed and the impact on the power produced by the GPV to be observed. The system continues to increment the operating voltage until the power generation starts to decrease. Figure 5 provides the $\mathrm{P} \& \mathrm{O}$ algorithm flowchart. 


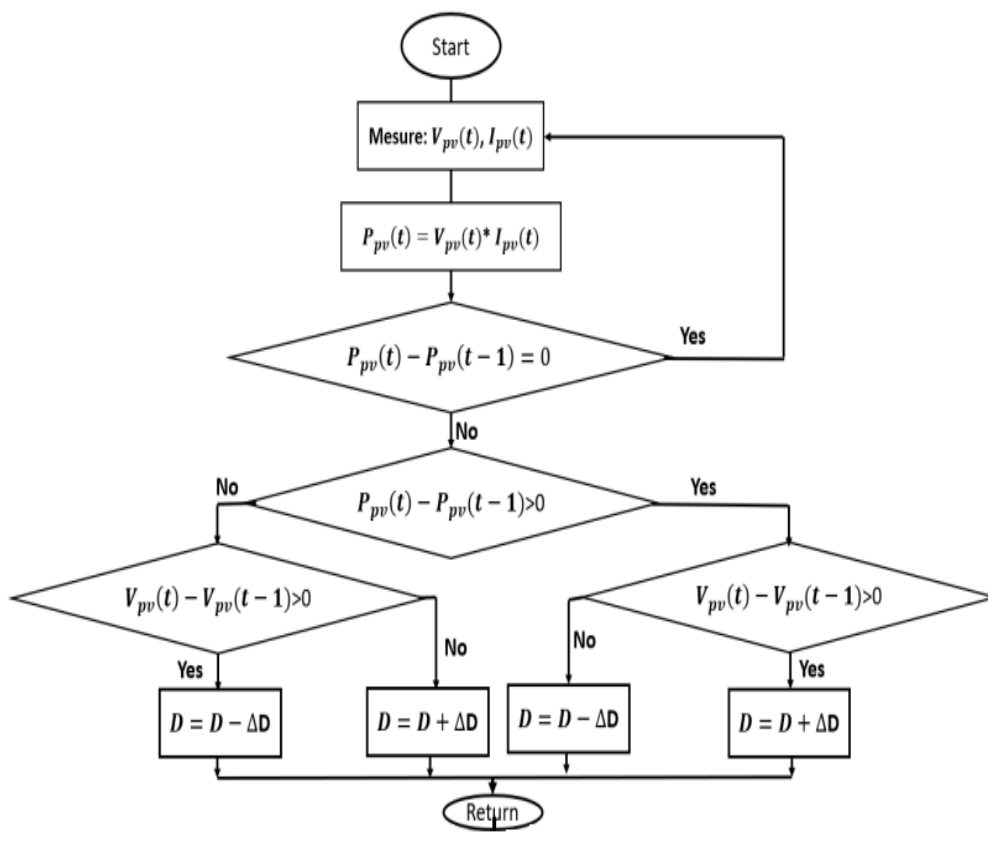

Figure 5. Command P\&O flowchart

\subsection{Genetic algorithm (AG)}

The GA are inspired by the process of evolution present in the natural world, such as selection, mutation inheritance and recombination to solve a problem. In the GA approach, set of gens are represented by the chromosome or individual. Each chromosome represents a solution or the given problem. The GA is used in this paper to determine the optimal parameters $\left(K_{p}\right.$ et $\left.K_{i}\right)$ of the PI controller. As shown (4) gives PI transfer function:

$$
F_{P I}(\mathrm{~S})=K_{p}+\frac{K_{i}}{S}
$$

The transfer function of single-phase DC/AC inverter out put current is given by (5):

$$
F_{i n v}(S)=\frac{V_{0}}{L . S}
$$

The feedback control of the inverter out put current is represented in Figure 6.

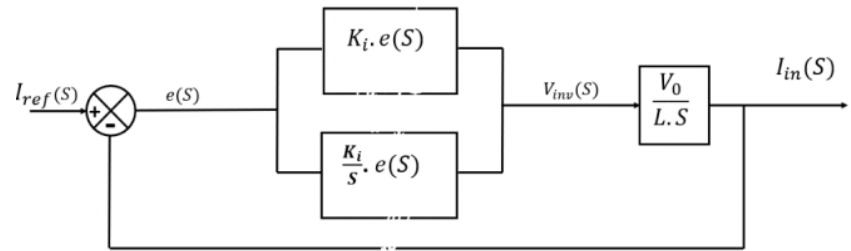

Figure 6. Unity feedback control system

$e(s)$ is the error between inverter current and the reference.

$$
e(t)=i_{\text {ref }}(\mathrm{t})-i_{\text {on }}(\mathrm{t})
$$

$\mathrm{V}(\mathrm{t})$ is inverter input expressed as:

$$
\mathrm{V}(\mathrm{t})=K_{p} \mathrm{e}(\mathrm{t})+K_{i} \int \mathrm{e}(\mathrm{t})
$$


The fitness function is given by (8).

$$
\text { Fitness function }=\int\left((\mathrm{e}(\mathrm{t}))^{2}+(\mathrm{V}(\mathrm{t}))^{2}\right) \mathrm{dt}
$$

The optimization of the PI controller parameters by using the genetic algoithm, is made as follow under MATLAB; i) define the function (file name); ii) define the transfert function: $\operatorname{tf}($ ' $S$ '); iii) define the transfert function of the studied system: (5); iv) define the parameters of the controller: $K_{p}$ et $K_{i}$; v) define the transfert function of the controller: (4); vi) define the error: (6); and vii) define the cost function: (8). Table 2 represents the GA parameters.

Table 2. GA parameter

\begin{tabular}{|c|c|c|}
\hline GA parameters & Methodes & Values \\
\hline Lower bounds [ Kp, Ki] & & {$\left[\begin{array}{ll}0 & 0\end{array}\right]$} \\
\hline Upper bounds [ Kp, Ki] & & [500 500] \\
\hline Population type & Double vector & 60 \\
\hline Selection & Stochastic uniform & \\
\hline Mutation & Uniform & \\
\hline Crossover & Arithmetic Crossover & \\
\hline
\end{tabular}

\section{RESULTS AND DISCUSSION}

The studied system is implemented under MATLAB/Simulink Software. Simulations are first done under standard temperature condition (STC). Figure 7 shows the maximum power point of the PV when the temperature and solar irradiation are at $1000 \mathrm{~W} / \mathrm{m}^{2}$ and 25 degrees Celsius (STC), respectively. The maximum power tracked are $846.14 \mathrm{~W}$ and $836.87 \mathrm{~W}$ with PSO and P\&O respectively. Hence, the efficiency is $97.9 \%$ and $96.8 \%$ with PSOthe $\mathrm{P} \& \mathrm{O}$, respectively. It can be noted that the meta-heuristic command (PSO) is more efficiency to extract the maximum power than the conventional method $(\mathrm{P} \& \mathrm{O})$.

To evaluate the efficiency of the proposed algorithms, the solar irradiation and the temperature have been variated as shown in Figure 8. The solar irradiation $\left(\mathrm{W} / \mathrm{m}^{2}\right)$ is variated from 800 to 500 , from 500 to 800 and from 800 to 600 . And the temperature (in degree Celsius) is also variated from 25 to 37 and from 37 to 22. Figure 9 illustrates the photovoltaic output generated by the two MPPT algorithms. The all used methods converge to the MPP but the PSO is faster to attain the MPP than P\&O as shown in Figure 9 (a) and gives less oscillations at the maximum point in Figure 9 (b). So PSO is better than P\&O to track the maximum point power.

Figures 10 and11 show the current supplied to the electrical network (EN) and its reference and the voltage of the EN. Figure 10 illustrates the voltage of the EN and the current supplied into the EN with the proposed method. It is noted that there is no phase shift between the EN voltage and current. This means that the reactive power is zero. The system produces a good quality of energy with active power only.

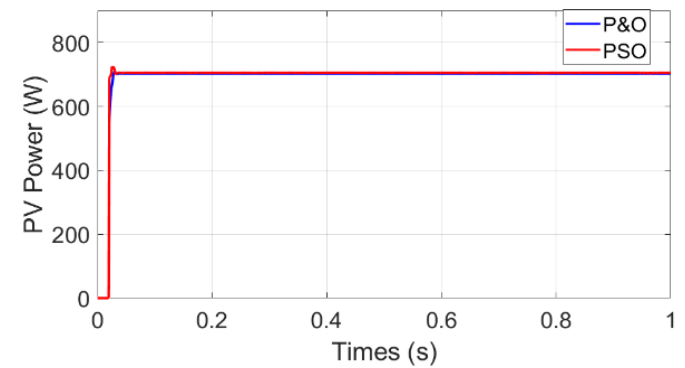

Figure 7. PV Power obtained with PSO and P\&O algorithms (standard test conditions)

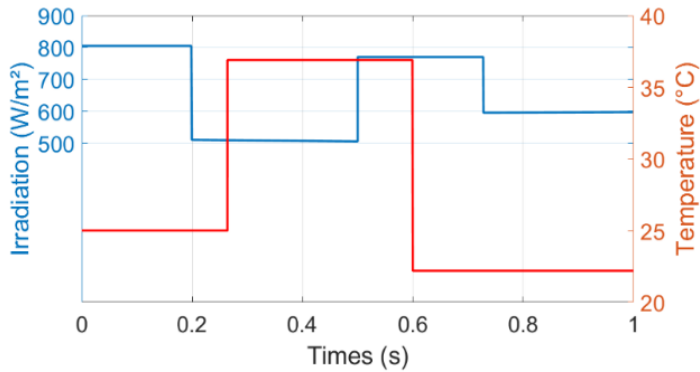

Figure 8. Variation of solar irradiation and temperatur 


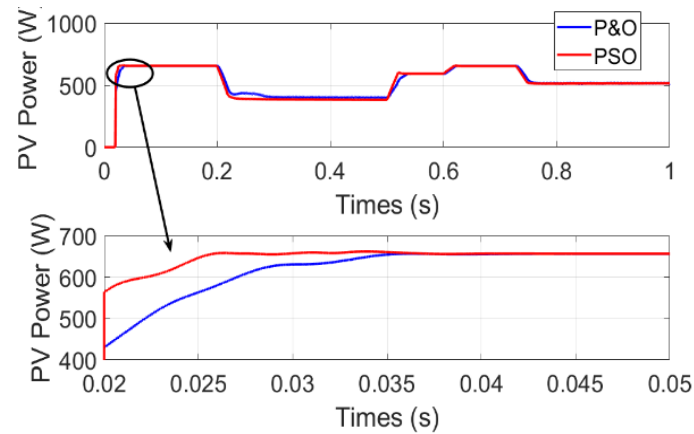

(a)

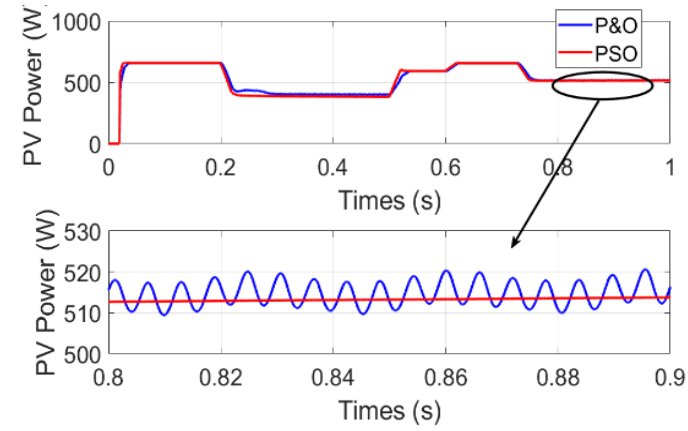

(b)

Figure 9. PV Power obtained with PSO and P\&O algorithms under variables weathers

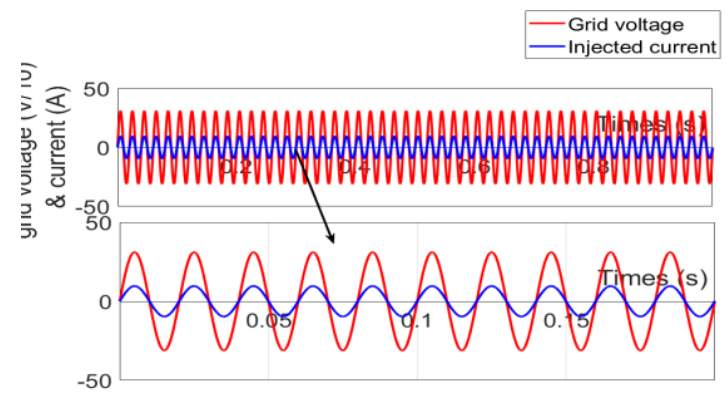

Figure 10. Current injected into the grid corrected by AGs-PI and the grid voltage

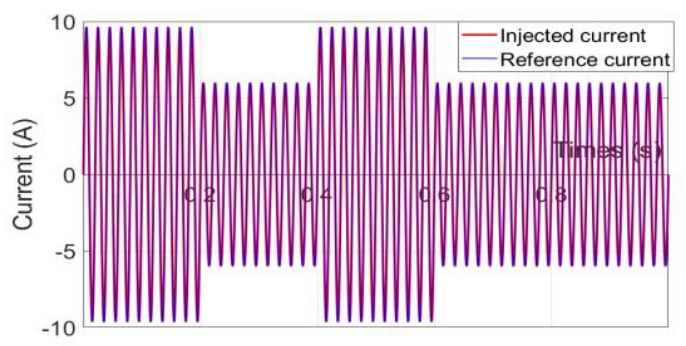

Figure 11. Injected current and this reference

The PI controller optimized by the genetic algorithm gives $0.89 \%$ of the total harmonic distortion (THD) less than $1.97 \%$ obtained in [22]. This value of THD satisfies the standard value given by NF C 15-100 and IEEE 519 (T HD <5\%) [15], [27], [28]. Figure 12 (a) shows the deference between the proposed method and PI Classique. In Figure 12 (b), it is noted clearly that the GA-PI is better than the PI method witch parameters are determined by Ziegler method and the adaptive neural network used in [22].

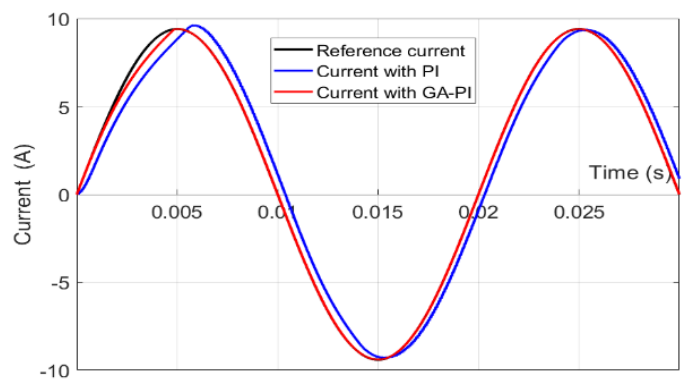

(a)

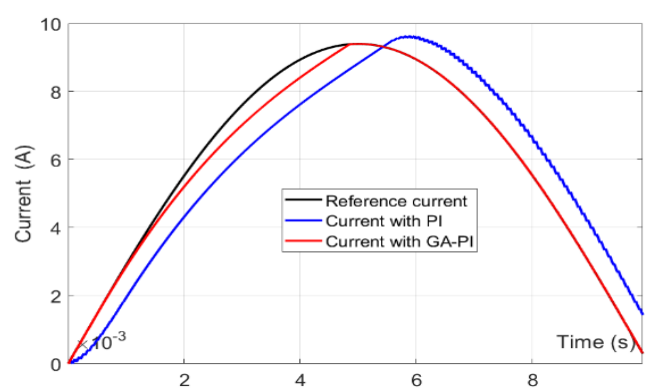

(b)

Figure 12. These figures are; (a) injected current and this reference controlled by GA-PI and PI Classique, (b) Zoom of Figure 12 (a)

\section{CONCLUSION}

A comparative study between a meta-heuristic algorithm PSO and a conventional MPPT command $\mathrm{P} \& \mathrm{O}$ has been executed in this document. Both algorithms are applied for PV power generation. Another meta-heuristic, the genetic algorithm is used in this work to optimize the PI parameters. The results of the simulations showed that the PSO is more efficient to extract the PV maximum power and fast than P\&O. The 
proposed method gave a low total harmonic distortion $(0.89 \%)$ and it is better than the conventional methods (Ziegler-Nicolson, and Naslin) used to determine the parameters of the correctors.

\section{REFERENCES}

[1] A. Harragand, and S. Messalti, "IC-based variable step size neuro-fuzzy MPPT Improving PV system performances," Energy Procedia, vol. 157, pp. 362-374, 2019, doi: 10.1016/j.egypro.2018.11.201.

[2] F. E. Lamzouri, E-M. Boufounas, A. Brahmi, and A. El Amrani, "Optimized TSMC Control Based MPPT for PV System under Variable Atmospheric Conditions Using PSO Algorithm,” Procedia Computer Science, vol. 170, pp. 887-892, 2020, doi: 10.1016/j.procs.2020.03.116.

[3] D. Pathak, G. Sagar, and P. Gaur, "An Application of Intelligent Non-linear Discrete-PID Controller for MPPT of PV System," Procedia Computer Science, vol. 167, pp. 1574-1583, 2020, doi: 10.1016/j.procs.2020.03.368.

[4] D. Pilakkat and S. Kanthalakshmi, "Single phase PV system operating under Partially Shaded Conditions with ABC-PO as MPPT algorithm for grid connected applications," Energy Reports, vol. 6, pp. 1910-1921, 2020, doi: 10.1016/j.egyr.2020.07.019.

[5] A. F. Mirza, M. Mansoor, Q. Ling, B. Yin, and M. Yaqoob Javed, "A Salp-Swarm Optimization based MPPT technique for harvesting maximum energy from PV systems under partial shading conditions," Energy Conversion and Management, 209, pp. 112-625, 2020, doi: 10.1016/j.enconman.2020.112625.

[6] M. V. da Rocha, L. P. Sampaio, and S. A. O. da Silva, "Comparative analysis of MPPT algorithms based on Bat algorithm for PV systems under partial shading condition," Sustainable Energy Technologies and Assessments, vol. 40, pp. 100-761, 2020, doi: 10.1016/j.seta.2020.100761.

[7] M. K. Behera and L. C. Saikia, "A new combined extreme learning machine variable steepest gradient ascent MPPT for PV system based on optimized PI-FOI cascade controller under uniform and partial shading conditions," Sustainable Energy Technologies and Assessments, vol. 42, pp. 100859, 2020, doi: 10.1016/j.seta.2020.100859.

[8] Sh. Li, "A variable-weather-parameter MPPT control strategy based on MPPT constraint conditions of PV system with inverter," Energy Conversion and Management, vol. 197, pp. 111873, 2019.

[9] M. Mansoor, A. F. Mirza, and Q. Ling, "Harris hawk optimization based MPPT control for PV systems under partial shading conditions," Journal of Cleaner Production, vol. 274, pp. 122857, 2020, doi: 10.1016/j.jclepro.2020.122857.

[10] P. Verma, R. Garg, and P. Mahajan, "Asymmetrical interval type- 2 fuzzy logic control based MPPT tuning for PV system under partial shading condition,” ISA Transactions, vol. 100, pp. 251-263, 2020, doi: 10.1016/j.isatra.2020.01.009.

[11] A. Elmelegi, M. Aly, E. Ahmed, and Abdullah G. Alharbi, "A simplified phase-shift PWM-based feedforward distributed MPPT method for gridconnected cascaded PV inverters," Solar Energy, vol. 187, pp. 1-12, 2019, doi: 10.1016/j.solener.2019.05.021.

[12] A. Raj, S. R. Arya, and J. Gupta, "Solar PV array-based DC-DC converter with MPPT for low power applications," Renewable Energy Focus, vol. 34, pp. 109-119, 2020, doi: 10.1016/j.ref.2020.05.003.

[13] B. A. Numan, A. M. Shakir, and A. L. Mahmood, "Photovoltaic array maximum power point tracking via modified perturbation and observation algorithm," International Journal of Power Electronics and Drive System, vol. 11, pp. 2007-2018, 2020, doi: 10.11591/ijpeds.v11.i4.pp2007-2018.

[14] X. Zhang, Q. Gao, Z. Guo, H. Zhang, M. Li, and F. Li, "Coordinated control strategy for a PV-storage gridconnected system based on a virtual synchronous generator," Global Energy Interconnection, vol. 3, pp. 51-59, 2020, doi: 10.1016/j.gloei.2020.03.003.

[15] M. Aourir et al., "Nonlinear control of multicellular single stage grid connected photovoltaic systems with shunt active power fltering capability," IFAC-Papers OnLine, vol. 53, pp. 12853-12858, 2020, doi: 10.1016/j.ifacol.2020.12.2091.

[16] S. Nadweh, O. Khaddam, G. Hayek, B. Atieh, and H. H. Alhelou, "Optimization of P \& PI controller parameters for variable speed drive systems using an ower pollination algorithm," Heliyon, vol. 6, pp. 04648, 2020, doi: 10.1016/j.heliyon.2020.e04648.

[17] M. S Chong, D. Umsonst, and H. Sandberg, "Local Local voltage voltage control control of Local voltage with Local voltage control," IFAC PapersOnLine, vol. 52, pp. 163-168, 2019, doi: 10.1016/j.ifacol.2019.12.152.

[18] A. M. Howlader, S. Sadoyama, Leon R. Roose, and Yan Chen, "Active power control to mitigate voltage and frequency deviations for the smart grid using smart PV inverters," Applied Energy, vol. 258, pp. 114000, 2020.

[19] I. Kim, and R. G. Harley, "Examination of the effect of the reactive power control of photovoltaic systems on electric power grids and the development of a voltage-regulation method that considers feeder impedance sensitivity," Electric Power Systems Research, vol. 180, pp. 106130, 2020, doi: 10.1016/j.epsr.2019.106130.

[20] B. Lekouaghet, A. Boukabou, N. Lourci, and K. Bedrine, "Control of PV grid connected systems using MPC technique and different inverter configuration models," Electric Power Systems Research, vol. 154, pp. 287-298, 2018, doi: 10.1016/j.epsr.2017.08.027

[21] P. Najafi, A. H. Viki, and M. Shahparasti, "Novel space vector-based control scheme with dc-link voltage balancing capability for 10 switch converters in bipolar hybrid microgrid," Sustainable Energy, Grids and Networks, vol. 20, pp. 100-256, 2019, doi: 10.1016/j.segan.2019.100256.

[22] J. P. Roselyn et al., "Design and implementation of fuzzy logic based modified real-reactive power control of inverter for low voltage ride through enhancement in grid connected solar PV system," Control Engineering Practice, vol. 101, pp. 104494, 2020, doi: 10.1016/j.conengprac.2020.104494. 
[23] S. F. Zarei, H. Mokhtari, M. A. Ghasemi, S. Peyghami, P. Davari, and F. Blaabjerg, "DC-link loop bandwidth selection strategy for grid-connected inverters considering power quality requirements," Electrical Power and Energy Systems, vol. 119, pp. 105879, 2020, doi: 10.1016/j.ijepes.2020.105879.

[24] G. Ganesan, M.K. Mishra, K. Jayaprakash, and P.J. Sureshbabu, "Simulation Study of Hysteresis Current Controlled Single-Phase Inverters for PhotoVoltaic Systems with Reduced Harmonics level," International Journal of Applied Engineering Research, vol. 13, pp. 4409-4414, 2018.

[25] M. H. Mahlooji, H. R. Mohammadi, and M. Rahimi, "A review on modeling and control of grid-connected photovoltaic inverters with LCL filter," Renewable and Sustainable Energy Reviews, vol. 81, pp. 563-578, 2018, doi: 10.1016/j.rser.2017.08.002.

[26] M. Lasheen, and M. A. Salam, "Maximum power point tracking using Hill Climbing and ANFIS techniques for PV applications: A review and a novel hybrid approach," Energy Conversion and Management, vol. 171, pp. 10021019, 2018, doi: 10.1016/j.enconman.2018.06.003.

[27] M. Al Talaq, and C. A. Belhaj, "Optimal PV Penetration for Power Losses Subject to Transient Stability and Harmonics," Procedia Computer Science, vol. 175, pp. 508-516, 2020, doi: 10.1016/j.procs.2020.07.072.

[28] J. Kaushal, and P. Basak, "Power quality control based on voltage sag/swell, unbalancing, frequency, THD and power factor using artificial neural network in PV integrated AC microgrid," Sustainable Energy, Grids and Networks, vol. 23, pp. 100365, 2020, doi: 10.1016/j.segan.2020.100365.

\section{BIOGRAPHIES OF AUTHORS}

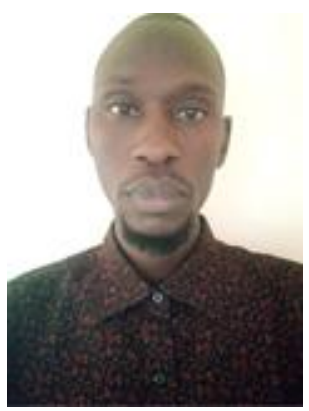

Mamadou Traore, is a $\mathrm{PhD}$ student from Alioune Diop University. He has a Master in Renewable Energy, Speciality Solar Energy in this university. He studies about energy optimization, inverter control, energy management and supervision of microgrid. Email: mamadou.traore@uadb.edu.sn, https://orcid.org/0000-0002-6383-8690.

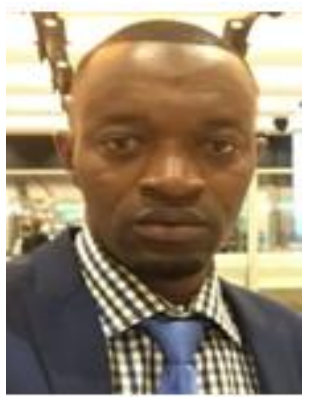

Alphousseyni Ndiaye received the Ph.D. degree from Higher Polytechnic School of Cheik Anta Diop University of Dakar, Senegal, in 2014. He is currently an Associate Professor with of Research Team Energetic System and Efficiency of Alioune Diop University of Bambey, Senegal since 2015. His current research interests include microgrids, electrical grid resiliency, energy selfconsumption and adaptive power electronics control based on Neuro-Fuzzy. Email: alphousseyni.ndiaye@uadb.edu.sn, https://orcid.org/0000-0003-4024-4256.

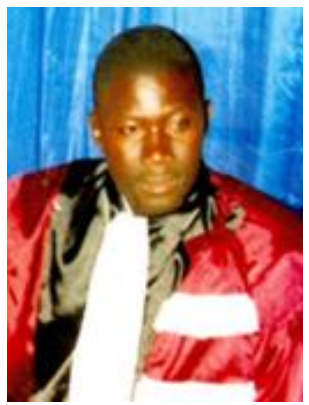

Senghane Mbodji is a Professor at Alioune Diop University, Bambey, Senegal. He is a specialist of Semiconductor Physics applied to Solar Energy. He holds two PhDs. He is an author or co-author of more than sixty publications in his field. To this end, his works are based to the concept of junction recombination velocity which permits me to determine all operating points of the solar cell: from the open circuit operating point to the short-circuit one. He used the steady state operating conditions, the transient state defined on two steady state conditions or the frequency dynamics state in $1 \mathrm{D}$ and $3 \mathrm{D}$ modeling studies. These studies helped him to calculate, based on the concept of "junction recombination velocity," the solar cell power, the open circuit photo-voltage, the effective diffusion length of carriers, the intrinsic junction recombination velocity which is related carriers lost to the junction of the solar cell, the back surface recombination velocity of the solar cell, the shunt and series resistance, to make simulations and validate the electric circuit types equivalent to the solar cell. A study on the effect of grain size and grain boundary recombination velocity on Shunt and series resistance has been made via the junction recombination velocity at the junction $(\mathrm{Sf})$. All these techniques have been used published in journals and conferences. And now, until 2013, he is working on the sizing of solar power plant, the others renewable energy sources such as wind and biomass, the Internet of Things (IoT) applied to energy, the waste management and sanitation. Email: senghane.mbodji@uadb.edu.sn, https://orcid.org/0000-0001-7235-5036. 